\title{
Assessment of the Techniques of Blood Pressure Measurement by Health Professionals
}

\author{
Eugenia Velludo Veiga, Maria Suely Nogueira, Evelin Capellari Cárnio, Sueli Marques, \\ Marco Aurélio S. Lavrador, Suzana Alves de Moraes, Luciana A. C. Souza, \\ Nereida K. C. Lima, Fernando Nobre
}

Ribeirão Preto, SP - Brazil

Objective - To assess blood pressure measurement by health professionals of a public hospital in São Paulo State.

Methods - Semi-structured interviews and direct observation were performed with a verification list according to the criteria reported by Perloff et al. One hundred and five health professionals took part in the study. After measuring blood pressure, the level of concordance between the way the procedure was performed and the recommended one was assessed.

Results - Nurses and nurse's aides abided by $40 \%$ of the recommended procedures for adequate blood pressure measurement. The other categories of health professionals (nursing and medicine teachers, physicians, residents, and nursing students) abided by approximately $70 \%$.

Conclusion - Permanent educational activities aiming at standardizing blood pressure measurement should be implemented among the different categories of health professionals.

Key words: blood pressure, blood pressure measurement, methods of blood pressure measurement

Escola de Enfermagem de Ribeirão Preto of USP and Hospital das Clínicas de Ribeirão Preto - FMUSP

Mailing address: Eugenia Velludo Veiga - Campus da USP - Escola de Enfermagem de Ribeirão Preto - Av. Bandeirantes, 3900 - 14040-902 - Ribeirão Preto, SP, Brazil - E-mail: evveiga@eerp.usp.br

English version by Stela Maris C. e Gandour
Systemic hypertension is considered one of the major risk factors of cardiovascular morbidity and mortality, accounting for $40 \%$ of the cases of early retirement and absenteeism in the workplace ${ }^{1,2}$.

Precise blood pressure measurement is an essential condition for the diagnosis of hypertension, because blood pressure elevation is usually the first sign of the disease. It is an easy and simple procedure; however, if certain principles are not obeyed, blood pressure measurement will be subjected to several factors of error with significant practical consequences ${ }^{3}$. Therefore, precise blood pressure measurement with the consequent establishment of a correct diagnosis of hypertension is important to determine criteria for the development of that procedure. Those criteria may relate to the environment, the observer, the patient, and the device used ${ }^{4-7}$.

The literature shows the need for standardizing the criteria for blood pressure measurement. In addition, blood pressure measurement should be performed in a systematic way by health professionals, implying the obtainment of real values of blood pressure, which may determine the adequate management and treatment of hypertension when present ${ }^{8-12}$.

Because of our involvement in teaching and researching blood pressure measurement at the undergraduate and postgraduate level to nursing and medical students, we felt the need to assess the blood pressure measuring procedure according to the criteria recommended by the American Heart Association in $1993^{6}$. We analyzed the daily assessment of blood pressure levels of patients hospitalized or followed up on an outpatient care basis at hospital, and observed mainly the health professionals performing that task.

This study aimed at assessing blood pressure measurement by the health professionals of a public hospital in São Paulo State.

\section{Methods}

The project was submitted to the Committee on Ethics and Research of the above-cited hospital and was appro- 
ved. After that, the directors of a nursing and medical schools were required to provide 2 lists as follows: 1) a list of the teachers working in the disciplines of the following units of hospital admission: general medicine, gynecology and obstetrics, surgery, neurology, orthopedics, otorhinolaryngology, and ophthalmology; 2) a list of 4th-grade students of the nursing school in 1996. The administration at the hospital was asked to provide a list of the 2nd-year residents, nurses, and nurse's aides in the above-cited specialties and units, which comprised 662 individuals. Of this population, a random sample of 138 individuals was obtained, corresponding to $20 \%$ of each professional category, of whom $33(24 \%)$ did not participate in the study for several reasons, such as vacation, day off, and leave of absence, which resulted in the assessment of 105 individuals.

A protocol was used for collecting the following data for identification of the individuals: professional category, age in years, sex, and place and year of graduation. The blood pressure measuring procedure was assessed by the following items: interaction with the examinee; patient's position, considering the sitting or lying down position; resting period of 3 to 5 minutes prior to blood pressure measurement; arm position at $45^{\circ}$, at the level of the heart; arm circumference measurement; selection of the inflatable rubber bag according to the arm circumference; cuff placement on a naked arm; adequately visible manometer; identification of the site of the brachial artery; cuff adequately involving the arm; previous determination of the inflation level through palpation; cuff deflation at a rate of 2 to $3 \mathrm{~mm} \mathrm{Hg} / \mathrm{s}$; 30 -second interval between 2 measurements; and position of the metallic cup of the stethoscope over the brachial artery. Through the semi-structured interview and direct observation, the following data were obtained: limb selected for blood pressure measurement; patient's position (sitting, lying down, standing); blood pressure value in $\mathrm{mm} \mathrm{Hg}$ obtained during the first and second measurements, if the latter occurred; the type of sphygmomanometer used in daily practice: aneroid or mercury column; and frequency of calibration of the devices.

Data were collected from May 1996 to December 1997 by 5 researchers previously trained in standardizing blood pressure measurement and completing the questionnaire.
The individuals participating in the study were informed about the objectives of the study, the reason why they were taking part in it, and they had to provide a written informed consent to take part in the study.

The observation and interview occurred at the workplace of each participant, with the previous election of the patient to be examined. Then, this patient was asked to have his blood pressure and arm circumference measured. The professional observed did not know about this.

Blood pressure was measured in an appropriate place with all required resources available for the professionals in the study, such as mercury column and aneroid sphygmomanometers, cuffs of different widths, stethoscope, measuring tape, and the option of a silent place if the professionals found necessary to have one for the procedure.

\section{Results}

One hundred and five individuals of different professional categories took part in this study (tab. I) and their ages ranged from 20 to 50 (mean of $33.6 \pm 10.1$ ) years. In regard to sex, 41 (39\%) were males.

Table II shows the distribution of the professionals according to category and clinical specialty. The "nursing student" category was not included because they did not work at a specific unit in the hospital.

Of the graduated individuals, $47.8 \%$ had concluded their courses 1 to 5 years before (tab. III).

Of other important factors for adequate blood pressure measurement, some variables, such as the number of measu-

\begin{tabular}{|llll|}
\hline \multicolumn{4}{|c|}{ Table I - Professional category, numbers, and percentage of the } \\
population studied
\end{tabular}

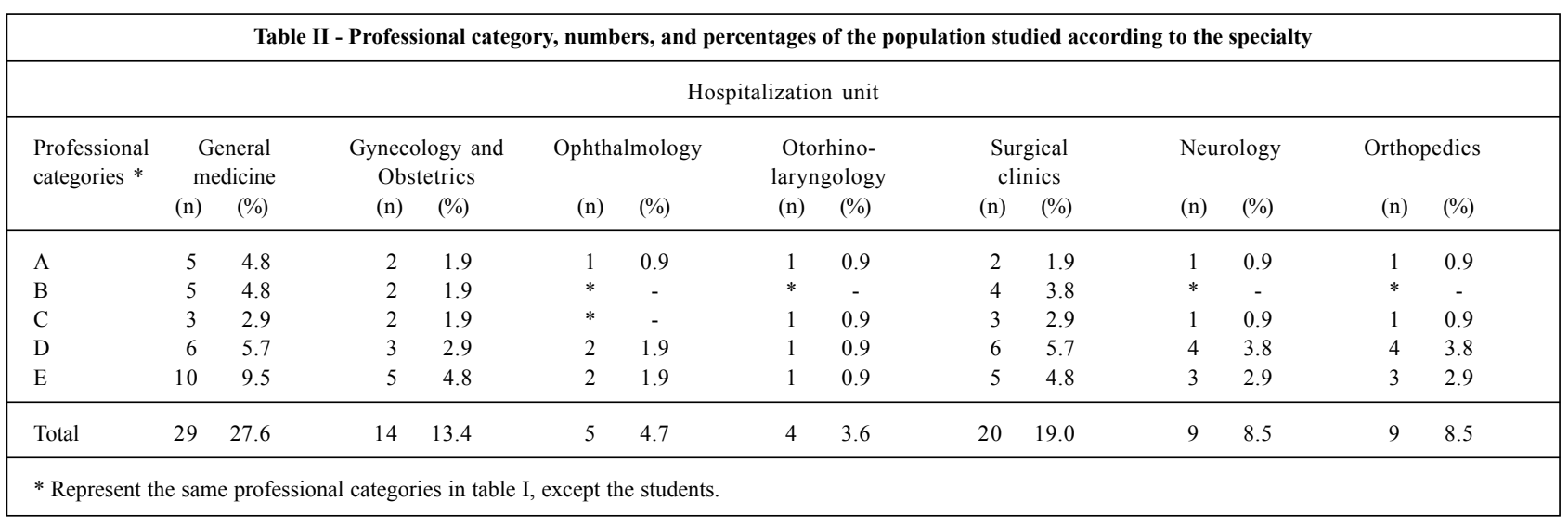


rements taken, preferred final digits, type of device used for measurement, and calibration of the devices, were also assessed in the study through direct observation and interview, after observing blood pressure measurement, using the verification list.

In regard to the number of measurements taken, most individuals $(66.7 \%)$ identified blood pressure values in a single measurement; $78 \%$ of the observers reported not having adequate cuffs for their professional practice. Table IV shows the distribution of the final digits recorded for systolic and diastolic blood pressure values, the preference for zero as the final digit in systolic blood pressure values in $77.1 \%$, and in diastolic blood pressure values in $74.3 \%$ of the measurements. In regard to the final digits, $17.2 \%$ of the individuals recorded digits between 2 and 8 for systolic blood pressure, and $14.4 \%$ for diastolic blood pressure, while $5.7 \%$ recorded odd final digits (from 1 to 9 ) for systolic blood pressure and $11.4 \%$ for diastolic blood pressure.

Table $\mathrm{V}$ shows the distribution of the number and percentages of the types of devices reported as routinely used by the participants.

In regard to calibration of the devices, table VI shows the frequency reported as used by the population evaluated.

Blood pressure measurement in this study comprised 16 steps described according to the recommendations of Perloff et $\mathrm{al}^{6}$. In regard to interaction with the patient, the explanation of the procedure to the patient was the most frequently performed step $(97.1 \%)$, while the selection of the adequate width of the cuff was performed only by $6.7 \%$ of the sample. Some of the different health professionals studied were observed not to perform several steps of the procedure.

Two categories of health professionals, nurses and nurse's aides, performed less than $50 \%$ of the steps recommended for the procedure, unlike the other professionals studied, the nursing and medicine teachers, the residents, and the nursing students, who followed approximately $70 \%$ of the steps.

Table VII shows the numbers and percentages of the different professional categories studied and the steps followed during blood pressure measurement. It is evident that only a minority of the professionals studied performed some important steps, such as the selection of the adequate cuff, the measurement of the arm circumference, and the 30 second intervals between 2 measurements.

\section{Discussion}

This study aimed at assessing the way blood pressure was measured by different health professionals at a hospital, considering the steps reported in the literature and defined in the methodology of this study. Several researchers have tried to identify whether the health professionals have been performing this procedure adequately, because it is directly related to the evaluation of a vital parameter ${ }^{3,13-16}$. In the assisting practice among different professionals and at different places, blood pressure measurement is not correctly taken, which may compromise the values obtained, and, consequently, the diagnosis, treatment, and control of hypertension. Recently, studies carried out in São Paulo ${ }^{13,14}$ have reported that most nurses ignore the meaning of blood pressure measurements. Other studies have also shown irregularities in this procedure ${ }^{15,16}$.

It is worth stressing the importance of this procedure among professionals who work at different clinics, in epidemiological research, at restricted units, or at outpatient care units. The number of studies reporting errors involving blood pressure measurement has increased lately, and they have been attributed to the devices, the examiners, and the examinees ${ }^{11}$. In addition to the diversity of professionals studied, most of them had graduated 1 to 5 years before. Therefore, we can infer that graduation courses may not be adequately preparing the professionals for performing this specific procedure. The formation of the nurse's aides stands out for its practical and fundamental approach, because they are specifically oriented to hospital practice.

This study analyzed a set of 16 steps for blood pressure measurement according to Perloff et $\mathrm{al}^{6}$.

In regard to indirect blood pressure measurement, the least performed step among the individuals studied was the selection of the adequate cuff, because only $7 \%$ of the individuals checked on that aspect.

It is clear that several steps have not been performed during blood pressure measurement, a fact that was observed in all professional categories studied. If the importance of this fact is considered in obtaining reliable blood pressure

\begin{tabular}{|c|c|c|c|c|c|c|c|c|c|c|c|c|}
\hline \multirow[t]{3}{*}{$\begin{array}{l}\text { Professional } \\
\text { category }\end{array}$} & \multicolumn{12}{|c|}{ Time after graduation (in years) } \\
\hline & \multicolumn{2}{|c|}{$1-5$} & \multicolumn{2}{|c|}{ 6-10 } & \multicolumn{2}{|c|}{$11-15$} & \multicolumn{2}{|c|}{$16-20$} & \multicolumn{2}{|c|}{$21-25$} & \multicolumn{2}{|c|}{$26-31$} \\
\hline & $\mathrm{N}$ & $\%$ & $\mathrm{~N}$ & $\%$ & $\mathrm{~N}$ & $\%$ & $\mathrm{~N}$ & $\%$ & $\mathrm{~N}$ & $\%$ & $\mathrm{~N}$ & $\%$ \\
\hline A & - & - & - & - & 1 & 1.1 & 3 & 3.3 & 5 & 5.5 & 4 & 4.4 \\
\hline B & - & - & 1 & 1.1 & 3 & 3.3 & 2 & 2.2 & 4 & 4.4 & 1 & 1.1 \\
\hline $\mathrm{C}$ & 3 & 3.3 & 4 & 4.4 & 2 & 2.2 & 1 & 1.1 & 1 & 1.1 & - & - \\
\hline $\mathrm{D}$ & 11 & 12.2 & 12 & 13.3 & - & - & 1 & 1.1 & 2 & 2.2 & - & - \\
\hline E & 29 & 32.2 & - & - & - & - & - & - & - & - & - & - \\
\hline Total & 43 & 47,8 & 17 & 18.8 & 6 & 6.6 & 7 & 7.7 & 12 & 13.2 & 5 & 5.5 \\
\hline
\end{tabular}




\begin{tabular}{|lcccccccc|}
\hline \multicolumn{7}{|c|}{$\begin{array}{c}\text { Table IV - Percentages of the final digits recorded for systolic and } \\
\text { diastolic blood pressure in the individuals assessed }\end{array}$} \\
\hline $\begin{array}{l}\text { Blood } \\
\text { pressure }\end{array}$ & 0 & 2 & 4 & 6 & 8 & $\begin{array}{c}\text { Final digits } \\
\text { odd } \\
\text { numbers }\end{array}$ & Total \\
\hline & & & & & & & & \\
\hline & $\%$ & $\%$ & $\%$ & $\%$ & $\%$ & $\%$ & $\%$ \\
Systolic & 77.1 & 8.6 & 1.9 & 2.9 & 3.8 & 5.7 & 100 \\
Diastolic & 74.3 & 6.7 & 2.9 & 2.9 & 1.9 & 11.4 & 100 \\
\hline
\end{tabular}

\begin{tabular}{|lcc|}
\hline \multicolumn{3}{|c|}{ Table $\mathbf{V}$ - Numbers and percentages of the devices reported as used in } \\
daily practice
\end{tabular}

values, the severity of these findings may be recognized, and they may be directly impairing the blood pressure values obtained. In the literature, several authors have reported the importance of careful blood pressure measurement, because the values obtained ensure the early detection of hypertension, its correct diagnosis and control, in addition to precisely defining its treatment ${ }^{3,6,8}$.

When asked, $78 \%$ of the individuals assessed reported not having cuffs of different dimensions available for blood pressure measurement. The width of the cuff influences the blood pressure values obtained; blood pressure is underestimated when larger cuffs are used and is overesti-

\begin{tabular}{|lrr|}
\hline \multicolumn{3}{|c|}{ Table VI - Numbers and percentages of the frequency of calibration } \\
of the devices reported
\end{tabular}

mated when smaller cuffs are used. According to the American Heart Association, the width of the rubber bag should be approximately $40 \%$ of the arm circumference ${ }^{17}$. Some studies have reported these differences of under- and overestimation in individuals of different age groups and in Brazilian pregnant women ${ }^{18-21}$. The rules for correction are very limited, because they cannot correct vascular reactivity and arm circumferences $<20$ and $>40 \mathrm{~cm}$, which are frequently found in elderly or undernourished adults and in obese individuals. The question of thin arms concerns researchers even more because it makes the early identification of high blood pressure values difficult and may compromise the identification of alterations that do not influence the health status and the quality of life of the individuals ${ }^{18-21}$. If health professionals are not assessing arm circumference at the time of blood pressure measurement, they are imposing important errors on the values obtained.

In regard to the intervals between measurements, $26.7 \%$ of the interviewees waited at least 30 seconds. Palpation of the radial pulse prior to cuff inflation is extremely important, mainly in the elderly, because of the possibility of calcification of the arteries and the auscultatory gap. Of the

\begin{tabular}{|c|c|c|c|c|c|c|c|}
\hline \multirow[b]{2}{*}{$\begin{array}{l}\text { Steps followed during blood } \\
\text { pressure measurement }\end{array}$} & \multicolumn{7}{|c|}{$\begin{array}{l}\text { ccording to the professiona } \\
\text { Professional categories }\end{array}$} \\
\hline & $\begin{array}{c}\text { Medicine } \\
\text { teacher } \\
\mathrm{N}=13\end{array}$ & $\begin{array}{c}\text { Nursing } \\
\text { teacher } \\
\mathrm{N}=11\end{array}$ & $\begin{array}{c}\text { Assisting } \\
\text { nurse } \\
\mathrm{N}=11\end{array}$ & $\begin{array}{c}\text { Nurse's } \\
\text { aide } \\
\mathrm{N}=26\end{array}$ & $\begin{array}{l}\text { Resident } \\
\qquad \mathrm{N}=29\end{array}$ & $\begin{array}{c}\text { Nursing } \\
\text { student } \\
\mathrm{N}=15\end{array}$ & $\begin{array}{c}\text { Total } \\
\mathrm{N}=105\end{array}$ \\
\hline & $\mathrm{N}$ & $\mathrm{N}$ & $\mathrm{n}$ & $\mathrm{n}$ & $\mathrm{n}$ & $\mathrm{N}$ & $\mathrm{n}$ \\
\hline 1) Interaction with the patient & 13 & 11 & 8 & 20 & 29 & 15 & 96 \\
\hline 2) Patient's position (sitting) & 7 & 11 & 3 & 6 & 5 & 9 & 41 \\
\hline 3) Patient's position (lying down) & 6 & 0 & 8 & 20 & 24 & 6 & 64 \\
\hline 4) Resting period ( 3 to 5 minutes) & 12 & 11 & 3 & 6 & 28 & 10 & 70 \\
\hline 5) Arm position ( $45^{\circ}$, at the heart's level) & 13 & 9 & 5 & 3 & 25 & 13 & 68 \\
\hline 6) Measurement of the arm circumference & 0 & 2 & 0 & 0 & 5 & 4 & 11 \\
\hline 7) Selection of the adequate cuff & 0 & 2 & 0 & 0 & 3 & 2 & 7 \\
\hline $\begin{array}{l}\text { 8) Blood pressure measured with the } \\
\text { cuff applied to the naked arm }\end{array}$ & 12 & 10 & 11 & 25 & 29 & 15 & 102 \\
\hline 9) Properly visible manometer & 13 & 10 & 8 & 12 & 29 & 15 & 87 \\
\hline 10) Identification of the site of the brachial artery & 10 & 10 & 4 & 6 & 29 & 15 & 74 \\
\hline $\begin{array}{l}\text { 11) Centralization of the rubber bag } \\
\text { over the brachial artery }\end{array}$ & 10 & 10 & 4 & 6 & 29 & 15 & 74 \\
\hline 12) Cuff adequately involving the arm & 12 & 10 & 11 & 16 & 28 & 15 & 92 \\
\hline $\begin{array}{l}\text { 13) Previous determination of the inflation } \\
\text { level (through palpation) }\end{array}$ & 8 & 8 & 0 & 2 & 21 & 3 & 42 \\
\hline 14) Deflation of the cuff at a rate of 2 to $3 \mathrm{~mm} \mathrm{Hg} / \mathrm{s}$ & 8 & 8 & 3 & 4 & 20 & 13 & 56 \\
\hline 15) 30 -second interval between 2 measurements & 4 & 2 & 0 & 0 & 18 & 3 & 27 \\
\hline $\begin{array}{l}\text { 16) Position of the stethoscope cup over the } \\
\text { brachial artery }\end{array}$ & 12 & 7 & 10 & 12 & 29 & 15 & 85 \\
\hline
\end{tabular}


individuals assessed, only $53.3 \%$ deflated the cuff at a rate between 2 and $3 \mathrm{mmHg} / \mathrm{s}$, as recommended ${ }^{8,12}$. Cuff deflation at a more rapid velocity makes it difficult to precisely establish both systolic and diastolic blood pressure values ${ }^{6,9,14}$. The adequate position of the upper limb and maintenance of the individual at rest for a period of 3 to 5 minutes prior to blood pressure measurement were steps performed by $64.8 \%$ and $66.7 \%$ of the individuals assessed, respectively. Previous rest for the above-cited period and maintenance of the upper limb at the level of the heart are fundamental procedures for obtainment of measurements that actually express blood pressure behavior ${ }^{9,10,14,22}$.

The acts of adequately involving the arm with the cuff and locating the brachial artery at the moment of blood pressure measurement were performed for approximately $70 \%$ of the individuals studied, representing a more acceptable and equally important percentage. The adequate placements of the stethoscope and manometer to properly visualize blood pressure values were procedures performed by $81 \%$ to $82.9 \%$ of the individuals, respectively; interaction with the patient was observed in $91.4 \%$ of the sample studied. Blood pressure was measured with the naked arm by $97.1 \%$ of the individuals. This fact may play an important role, mainly because clothing may interfere with the arm width, causing an error in measurement.

Another fact that influences the obtainment of correct blood pressure values is the number of measurements. One single measurement was taken by $66.7 \%$ of the participants, who considered this correct.

In regard to the blood pressure values obtained, zero was recorded as the final digit for systolic blood pressure by $77.1 \%$ of the participants and for diastolic blood pressure by $74.3 \%$. Considering the frequency of the steps followed by the different professionals, nurses and the nurse's aides were those who less frequently followed the steps, which had been ideally proposed to correct blood pressure measurement. This is very preoccupying, because these professional categories act improperly on daily blood pressure measurement.

In conclusion, the need to improve observance of the steps of blood pressure measurement was identified in all professional categories studied. Greater attention should be paid to the factors of errors closely related to obtainment of blood pressure values, such as environment, the individual, the observer, and the device. Learning and teaching strategies regarding blood pressure measurement are urgently required, such as updating courses, investments in continuing education, and the insertion of specific contents in undergraduate and postgraduate courses. The multidisciplinary approach involving early detection, treatment, and control of hypertension requires that blood pressure measurement be effectively performed for the obtainment of reliable data and precise diagnoses.

\section{References}

1. Ministério da Saúde - Brasil. Secretaria de Assistência à Saúde. Coordenação de Doenças Cardiovasculares. Controle da Hipertensão Arterial: Uma proposta de integração ensino-serviço. Rio de Janeiro: CDCV/Nunetes, 1993: 232p.

2. Spritzer N. Epidemiologia da hipertensão arterial sistêmica. Medicina 1996;29: 199-213.

3. Pierin AMG, Gomes MAM. A medida da pressão arterial em casa. Revista da Sociedade Brasileira de Hipertensão 1998; 1: 36.

4. Lehane A, O'Malley K, O'Brien ET. Reporting of blood pressure data in medical journals. Br Med J 1980; 281: 1603-4.

5. Roche V, O'Malley K o'Brien ET. How "scientific" is blood pressure measurement in leading medical Journals? J Hypertens 1990; 8: 21167-8.

6. PerloffD, Grim C, Flack J, et al. Human blood pressure determination by sphygmomanometry. Circulation 1993; 88: 2460-70.

7. Petrie JC, O'Brien ET, Litller WA, Swiet M. Recommendations on blood pressure measurement. BrMed J 1986; 293: 611-5.

8. II Consenso Brasileiro para o tratamento da Hipertensão Arterial. Arq Bras Cardiol 1994: 16(supl. 2): S257-68.

9. III Consenso Brasileiro para o tratamento da Hipertensão Arterial. Rev Bras Hipertens 1999: 67-106.

10. VI Joint National Committee on Prevention Detection, Evaluation and treatment of high blood pressure. Arch Int Med 1997; 157: 2413-45.

11. Holanda HEM, Mion JD, Pierin AMG. Medida da pressão arterial: critérios empregados em artigos científicos de periódicos brasileiros. Arq Bras Cardiol 1997; 68: 433-6.

12. Mion Jr D, Pierin A, Krasilcic S, et al. Diagnóstico da hipertensão arterial. Medicina 1996; 29: 193-8.

13. Araújo TL, Arcuri EAM. Influência de fatores anátomo fisiológicos na medida in- direta da pressão arterial: identificação do conhecimento dos enfermeiros. Rev Latino-Am Enfermagem 1998; 6:21-9.

14. Araújo TL, Arcuri EAM, Martins E. Instrumentação na medida da pressão arterial: aspectos históricos, conceituais e fontes de erro. Rev Esc Enf USP 1998; 32: 33-41.

15. Santos SB, Jesus CAC, Kamada I, Jesus PC, Junqueira Jr LF. Avaliação da técnica da medida da pressão arterial. II Congresso de Iniciação Científica da UnB, Brasília, DF, 1996; (resumo): 84.

16. Carvalho JS, Jesus CAC, Kamada I, Jesus PC, Junqueira Jr. LF. Avaliação do conhecimento teórico que fundamenta a medida da pressão arterial. II Congresso de Iniciação Científica da UnB, Brasília, DF, 1996; (resumo): 83.

17. Fröhlich ED, Grim C, Labarthe DR, et al. Recommendations for human blood pressure determination by sphygmomanometers Hypertension. Circulation 1988; 11(supp 1): 210-22.

18. Oliveira SMJV. Influência da largura do manguito na medida da pressão arterial no ciclo grávido-puerperal.(Tese Doutorado). São Paulo: Escola de Enfermagem, Universidade de São Paulo, 1997: 145p.

19. VeigaEV. Medida indireta da pressão arterial em função da largura do manguito, em escolares de 6 a 10 anos de idade. (Tese Doutorado). Ribeirão Preto: Escola de Enfermagem de Ribeirão Preto, USP, 1995: 162p.

20. Arcuri EAM. Estudo comparativo da medida indireta da pressão arterial com manguito de largura correta e com manguito de largura padrão (Tese Doutorado) São Paulo: Instituto de Ciências Biomédicas da Universidade de São Paulo, 1985: 175p.

21. Arcuri EAM. Manguito do esfigmomanômetro e diagnóstico de hipertensão arterial sistêmica. Arq Bras Cardiol 1989; 52: 181-3.

22. Beck FW, Weaver JM, Blozis GG, Unverferth DV. Effect of arm position and arm support on indirect blood pressure measurements made in a dental chair. JAMA 1983; 106: 637-45. 